\title{
Parental stress in mothers of children and adolescents with cerebral palsy
}

\author{
Maysa Ferreira Martins Ribeiro ${ }^{1}$ \\ Ana Luiza Lima Sousa ${ }^{2}$ \\ Luc Vandenberghe $^{3}$ \\ Celmo Celeno Porto ${ }^{4}$
}

Objectives: to evaluate parental stress of mothers of children and adolescents with cerebral palsy; to verify whether parental stress undergoes variations according to the level of motor compromise, the child's phase of life, and sociodemographic variables. Method: a cross-sectional, descriptive study, with 223 mothers of children and adolescents with cerebral palsy. Results: $45.3 \%$ of the mothers presented high levels of stress; there were differences in stress between mothers of children with mild and severe motor impairment; mothers of older children were more stressed than mothers of younger children and of adolescents; paid work and leisure activities reduced the stress. Conclusion: mothers of children and adolescents with cerebral palsy, whose children present mild to severe motor impairment are vulnerable to parental stress. Paid work and leisure activities were the factors that contributed most to reducing the stress.

Descriptors: Cerebral Palsy; Stress, Psychological; Mothers; Child; Adolescent.

\footnotetext{
${ }^{1}$ Doctoral student, Universidade Federal de Goiás, Goiânia, GO, Brasil. Assistant Professor, Pontifícia Universidade Católica de Goiás, Goiânia, GO, Brazil. Scholarship holder from Fundação de Amparo à Pesquisa do Estado de Goiás (FAPEG).

${ }^{2}$ PhD, Associate Professor, Faculdade de Enfermagem, Universidade Federal de Goiás, Goiânia, GO, Brazil.

${ }^{3} \mathrm{PhD}$, Adjunct Professor, Pontifícia Universidade Católica de Goiás, Goiânia, GO, Brazil.

${ }^{4}$ PhD, Emeritus Professor, Faculdade de Medicina, Universidade Federal de Goiás, Goiânia, GO, Brazil.
}

\section{Corresponding Author:}

Maysa Ferreira Martins Ribeiro

Rua S-02, 59, Apto. 101

Edifício Marina Del Rel

Setor Bela Vista

CEP: 74823-430, Goiânia, GO, Brasil

E-mail: maysafmr@yahoo.com.br
Copyright (c) 2014 Revista Latino-Americana de Enfermagem This is an Open Access article distributed under the terms of the Creative Commons Attribution Non-Commercial License (CC BY-NC).

This license lets others distribute, remix, tweak, and build upon your work non-commercially, and although their new works must also acknowledge you and be non-commercial, they don't have to license their derivative works on the same terms. 


\section{Introduction}

Among the chronic conditions that arise in childhood cerebral palsy is the most common cause of disability, with a prevalence of 2 to 3 cases per 1000 live births. It is a serious disorder that has a great impact on the life of the person affected, on the family dynamics, on society, and on public policies, as it represents a chronic and complex condition that generates high costs. Motor function impaired is the main characteristic. However, patients may present sensory, intellectual, and communication deficits and complex limitations in selfcare functions ${ }^{(1-2)}$. The severity of the motor impairment can be classified into five levels using the Gross Motor Function Classification System (GMFCS): from Level I, which indicates less motor impairment, i.e., when the patient is able to walk without limitations, to level $\mathrm{V}$, the classification expressing severe motor impairment and the need for a wheelchair for mobility(2).

The emphasis on healthcare for children with cerebral palsy leads to the family also being better assisted during the childhood of the children. However, there are notable limitations in the specialized services to meet the needs of adolescents and adults with cerebral palsy, as well as their family members and caregivers $^{(3-4)}$. The financial investments are insufficient, there is a shortage of skilled professionals, and the healthcare actions are fragmented ${ }^{(5)}$. The physical and psychological health of the parents, especially the mother, as the principal person responsible for the care, is influenced by the behavior and needs of the children $^{(3-4)}$. In a European study conducted in 2011 with 818 parents of children with cerebral palsy, it was observed that $36 \%$ of them presented high levels of parental stress, which is significant when compared with the rate of $5 \%$ in the general population(6).

With the observation that stress is multidetermined and influenced by the characteristics of the children and parents, in 1983 the psychologist Richard Abidin published the first version of the Parenting Stress Index (PSI), an instrument consisting of 101 items. In 1995 the same author published the short version of the PSI (Parenting Stress Index Short Form - PSI/SF), with 36 items. These instruments measure the perception of the parents regarding the demands of the child and includes questions related to the characteristics of the child that have an impact on the parents ${ }^{(7)}$. The changes in behavior, the psychological and emotional disturbances of the children, and the need for continuing and specialized care are factors associated with higher levels of stress $^{(3,8)}$. Some studies indicate a relationship between motor impairment level of the children and stress experienced by the parents ${ }^{(3,9)}$, however, others did not find this association ${ }^{(4,10)}$. It should be noted that these studies focused on families of children with less motor and functional impairment. The stress experienced by the mothers causes illness and has a negative impact on the family dynamics and the social context. In addition, parental stress influences care practices, making the mothers more likely to be violent and neglectful, and to worsen the behavioral problems of the children. Hence the importance of identifying groups at risk and referring them for clinical intervention.

The aims of this study were: to assess parental stress of mothers of children and adolescents with cerebral palsy; to verify whether parental stress undergoes variations depending on level of motor impairment, stage of life of the children, and sociodemographic variables.

\section{Methods}

This cross-sectional, descriptive study was carried out in four rehabilitation institutes in the city of Goiânia/ Goiás. The project was approved by the Research Ethics Committee, protocol No.CEP/HC/UFG 173/2010, and developed in accordance with the recommendations of Resolution No. 196/96 of the National Health Council. The following inclusion criteria were adopted: mothers of children with cerebral palsy; mothers of children in the age group eight months to nine years and eleven months; mothers of adolescents aged between ten years and nineteen years and eleven months; mothers whose children were classified as levels I, II, IV and V according to the GMFCS. The exclusion criteria were: mothers who had more than one child with cerebral palsy; mothers whose children had other clinical condition associated with cerebral palsy; mothers of children classified in level III according to the GMFCS - this level is intermediate and does not allow a clear evaluation of the motor differences presented in cerebral palsy patients. The sample size was calculated using the two-tailed hypothesis test that defined the size as 144 mothers, with 36 in each group. The power of the test was $80.0 \%$. Data were collected from a larger number of mothers, 54\% more, to avoid sample loss and to increase the strength of the analysis. The final sample consisted of 223 mothers, 52 mothers of children classified as level I, 44 as level II, 43 as level IV, and 84 as level $\mathrm{V}$ according to the GMFCS. Of these, 
58 were mothers of younger children (eight months to two years and eleven months); 96 mothers of older children (three years to nine years and eleven months); and 69 mothers of adolescents (ten years to nineteen years and eleven months). A pilot study was conducted with a similar population, however, different from that which would be the target of the main study.

The mothers were approached individually, invited to participate as volunteers in the study, and given detailed explanations regarding the study. After signing the terms of free prior informed consent the data collection procedures were started. The instruments were applied in the form of individual interviews in a private room within the institutions, between August and December 2011. The average length of the interview was 20 minutes. The Parental Stress Index in the Short Form (PSI/SF), the Gross Motor Function Classification System (GMFCS), and a Sociodemographic Questionnaire were used.

The PSI/SF is widely used in research worldwide to evaluate parental stress, including studies with parents of children with cerebral palsy. In Brazil, the instrument has been translated and used in scientific articles(11-13). It consists of 36 items divided into three subscales: "parental distress", "parent-child dysfunctional interaction", and "difficult child", with 12 items each. The "parental distress" subscale is related to the distress and anguish that the father/mother experience in exercising their roles and how the requirements of the child may restrict the social participation of the parents; the "parent-child dysfunctional interaction" subscale assesses the representations that the parent has of their child, their interaction with it and the extent to which the child meets the expectations of the parents; the "difficult child" subscale focuses on the behavioral characteristics of the child and how these impact on the parents. For each question investigated, there is a set of propositions that compose a Likert type scale of five items (from 1 = strongly disagree to $5=$ strongly agree). The sum of the points attributed to each item defines the total score, which can range from 36 to 180 points. There are cutoff scores for each subscale and for the total questionnaire, with higher scores indicating higher levels of parental stress $^{(11)}$. Levels above the cutoff points indicate the need for a more detailed evaluation(11-13).

The cross-cultural adaptation of the GMFCS for Brazil has been performed(14-15), with this instrument allowing the measurement of the level of ability to perform gross motor activities in people with cerebral palsy. The patient classified as level I can walk, run and jump, but with impairments in speed, coordination and balance; level II patients can walk and have minimal ability to run and jump; level III patients can only walk with assistive mobility devices; in level IV independent mobility is very limited; and in level $\mathrm{V}$ all motor functions are severely limited(15).

The Sociodemographic Questionnaire included data regarding maternal age, schooling, family income, receipt of social benefits, profession/work, marital status, number of children, participation in leisure activities, type of transport, and psychological counseling. The data were recorded in a Microsoft Excel spreadsheet and analyzed using the Statistical Package for the Social Sciences (SPSS) program. Regarding the qualitative variables, associations between the groups of mothers were studied using the Chi-square test. Spearman's correlation coefficient was also used. Multivariate analysis was performed by applying logistic regression. Four models were constructed, each of which considered the total questionnaire and one of the three subscales as the outcome. The independent variables for each model were those that presented values of $p<0.20$ in the univariate analysis. For all tests, a significance level of $5 \%(p<0.05)$ was used. The internal validity of the total PSI/SF questionnaire and of each of the subscales was evaluated through Cronbach's alpha coefficient.

\section{Results}

The sample was comprised of 223 mothers, with a mean age of 32.5 years (SD \pm 7.97 ); the youngest mother was 17 and the oldest 58 years of age. For the presentation of the sociodemographic variables the mothers were categorized into two groups, according to the GMFCS levels of the children. The mothers of children with mild motor impairment were in one group, with levels I/II GMFCS classifications, and the mothers of children with severe motor impairment, levels IV/V, in the other group (Table 1).

The variables related to schooling, marital status, profession/work, and the practice of leisure activities had a similar distribution among the groups. The average family income was $\mathrm{R} \$ 1,200.00$ (SD \pm 954.86 ). In the majority of cases $(88.3 \%)$ the mothers were responsible for caring for the child most of the time. Only $10.8 \%$ of them were receiving psychological monitoring. The mean age of the 58 younger children was 17.6 months ( $\mathrm{SD} \pm 6.06$ ). Among the 96 older children, the mean age was five and a half years ( $S D \pm 1.90)$. The mean age of the 66 adolescents was 13 years (SD \pm 2.70$)$. 
Table 1 - Characterization of the mothers according to the sociodemographic variables and GMFCS levels. Goiânia, GO, Brazil 2012

\begin{tabular}{|c|c|c|c|c|c|}
\hline & \multicolumn{2}{|c|}{ Group I/II } & \multicolumn{2}{|c|}{ Group IV/V } & \multirow{2}{*}{$p^{*}$} \\
\hline & n (96) & $\%$ & $\mathrm{n}(127)$ & $\%$ & \\
\hline Schooling & & & & & 0.105 \\
\hline Illiterate & 03 & 3.1 & - & - & \\
\hline Complete/Incomplete Elementary Education & 29 & 30.2 & 33 & 26.0 & \\
\hline Complete/Incomplete High School Education & 53 & 55.2 & 84 & 66.1 & \\
\hline Complete/Incomplete Higher Education & 11 & 11.5 & 10 & 7.9 & \\
\hline Marital status & & & & & 0.658 \\
\hline Single & 19 & 19.8 & 31 & 24.4 & \\
\hline Married/cohabiting & 69 & 71.9 & 82 & 64.6 & \\
\hline Divorced & 06 & 6.3 & 09 & 7.1 & \\
\hline Widowed & 02 & 2.1 & 05 & 3.9 & \\
\hline Profession/Work & & & & & 0.674 \\
\hline In the home & 51 & 53.1 & 73 & 57.5 & \\
\hline Informal work & 31 & 32.3 & 39 & 30.7 & \\
\hline Formal work & 14 & 14.6 & 14 & 11.0 & \\
\hline Leisure activity & & & & & 0.474 \\
\hline Yes & 37 & 38.5 & 55 & 43.3 & \\
\hline No & 59 & 61.5 & 72 & 56.7 & \\
\hline
\end{tabular}

*Significance level $\mathrm{p}$

The internal validity of the PSI/SF for the total questionnaire was $\alpha=0.855$; for the "parental distress" subscale $\alpha=0.813$; for the "dysfunctional interactions" subscale $\alpha=0.741$; and for the "difficult child" subscale $\alpha=0.705$, demonstrating its reliability and accuracy. The distribution of the number and percentage of mothers with stress levels below, and equal to or above the cutoff point for each subscale and for the total questionnaire were evaluated (Table 2).
In the total questionnaire $45.3 \%$ of the mothers presented stress scores above the cutoff point, with a higher proportion of mothers in the "parental distress" subscale $63.2 \% \quad(n=141 ; p<0.001)$. In the total questionnaire, there was no difference in the proportion of stressed mothers when comparing groups I/II and IV/V, however, there was a higher proportion of mothers of children in levels I/II $(n=31 ; 57.6 \% ; p=0.014)$ in the "difficult child" subscale (Table 3 ).

Table 2 - Number and percentage of mothers with stress, in each subscale and in the total questionnaire. Goiânia, GO, Brazil 2012

\begin{tabular}{|c|c|c|c|c|c|}
\hline \multirow{2}{*}{$\begin{array}{c}\text { The Parental Stress Index Short Form (PSI/SF) } \\
\text { Subscales and Total Questionnaire }\end{array}$} & \multicolumn{2}{|c|}{ Score $<$} & \multicolumn{2}{|c|}{ Score $\geq$} & \multirow{2}{*}{$p^{*}$} \\
\hline & $\mathbf{n}$ & $\%$ & $\mathbf{n}$ & $\%$ & \\
\hline Parental distress $(\geq 33)^{\dagger}$ & 82 & 36.8 & 141 & 63.2 & 0.000 \\
\hline Dysfunctional interaction $(\geq 28)^{\dagger}$ & 149 & 66.8 & 74 & 33.2 & 0.000 \\
\hline Difficult child $(\geq 37)^{\dagger}$ & 169 & 75.8 & 54 & 24.2 & 0.000 \\
\hline Total Questionnaire $(\geq 94)^{\dagger}$ & 122 & 54.7 & 101 & 45.3 & 0.160 \\
\hline
\end{tabular}

*Significance level $p$

${ }^{\dagger}$ Cutoff point for the stress to be considered pathological

Table 3 - Number and frequency of mothers with stress in each subscale and in the total questionnaire of the PSI/SF, according to the groups I/II and IV/V. Goiânia, GO, Brazil 2012

\begin{tabular}{|c|c|c|c|c|c|}
\hline \multirow{2}{*}{$\begin{array}{c}\text { The Parental Stress Index Short Form (PSI/SF) } \\
\text { Subscales and Total Questionnaire }\end{array}$} & \multicolumn{2}{|c|}{$\begin{array}{c}\begin{array}{c}\text { Group I/II } \\
\mathrm{N}=96\end{array} \\
\text { Score }<\end{array}$} & \multicolumn{2}{|c|}{$\begin{array}{c}\begin{array}{c}\text { Group IV/V } \\
\mathrm{N}=127\end{array} \\
\text { Score } \geq\end{array}$} & \multirow[t]{2}{*}{$p^{*}$} \\
\hline & $\mathbf{n}$ & $\%$ & $\mathbf{n}$ & $\%$ & \\
\hline Parental distress $(\geq 33)^{\dagger}$ & 59 & 41.8 & 82 & 58.2 & 0.634 \\
\hline Dysfunctional interaction $(\geq 28)^{\dagger}$ & 34 & 45.9 & 40 & 54.1 & 0.538 \\
\hline Difficult child $(\geq 37)^{\dagger}$ & 31 & 57.6 & 23 & 42.6 & 0.014 \\
\hline Total Questionnaire $(\geq 94)^{\dagger}$ & 44 & 43.6 & 57 & 56.4 & 0.888 \\
\hline
\end{tabular}

*Significance level $p$

*Cutoff point for the stress to be considered pathological 
Figure 1 shows the distribution of mothers with stress in each subscale and in the total questionnaire according to the age group of the children. As can be seen, the mothers of older children presented a higher proportion of stress in all the subscales and in the total questionnaire. In the "parental distress" subscale there was no significant difference $(n=68 ; 48.2 \% ; p=0.049)$ compared to the other age groups.

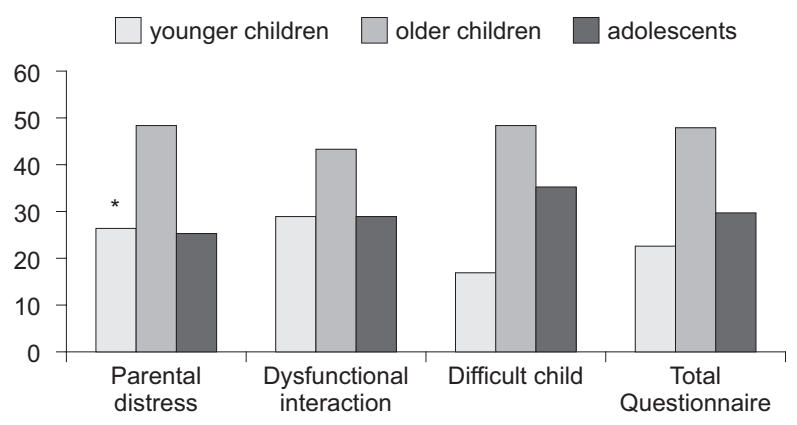

*significance level $p=0.04$

Figure 1 - Mothers with stress in each subscale and in the total questionnaire according to the age of the children. Goiânia, GO, Brazil 2012

Figure 2 presents the distribution of the mothers with stress according to the groups I/II and IV/V and the age group of the children. Proportionally more mothers of children in the IV/V group were stressed than those with children in the I/II group; however, the difference between the groups was not significant. Among the adolescents the situation was reversed, with mothers of adolescents in group I/II more stressed than those of the IV/V group $(p=0.027)$.

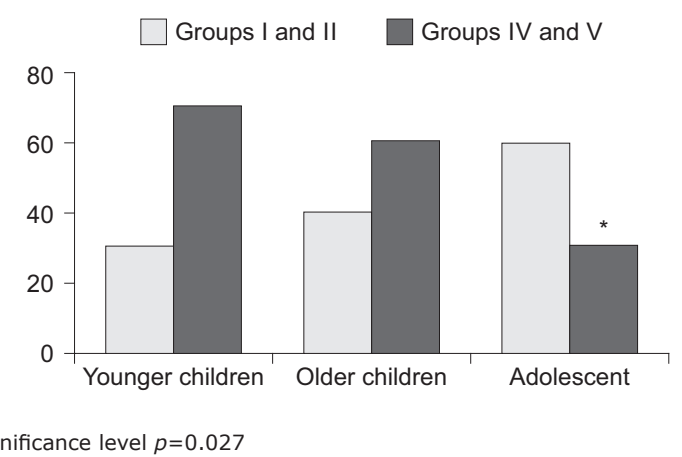

Figure 2 - Mothers with stress according to the groups I/ II and IV/V and the age groups of the children. Goiânia, GO, Brazil 2012
The schooling had a weak but significant correlation with the "parental distress" subscale: mothers with more schooling had less stress in this subscale $(r=-0.15$; $p=0.02)$; the same was the case in the total questionnaire $(r=-0.14 ; p=0.03)$. The age of the children, motor impairment of the children, family income, and number of children were not associated with the presence of stress. According to the multivariate analysis, the age of the children, the level of motor impairment, the level of maternal education, and family income did not explain the stress of mothers. In contrast, mothers without leisure activities were 4.96 times more likely to be stressed, in the total questionnaire $(O R=4.969$; $\mathrm{CI}=2.65-9.33 ; \mathrm{p}<0.001)$; in addition, mothers who had no paid work were 2.62 times more likely to be stressed, in the "parental distress" subscale $(O R=2.620$; $C I=1.099-6.247 ; p=0.030$ ).

\section{Discussion}

Almost half of the mothers had high levels of parental stress, corroborating a literature review(16). There was a greater identification of stress in the "parental distress" subscale, which evaluates how the requirements of the child cause distress and restrict the social participation of the mothers. The mothers see their life project modified due to the need to care for their children and tend to feel less satisfied with life. Low self-esteem, lack of family and social support, limited financial resources, the feelings of frustration/loss in value, and the daily overload of tasks caused anxiety, stress and repercussions in physical and psychological health. With this, the mothers felt less able to accommodate and support the children and satisfaction with the parental role also decreased ${ }^{(6,17)}$. These mothers are more likely to have the care of their family members as their principal activity and when performing paid work, prefer informal labor activities, due to the possibility of working from home and greater flexibility in working hours. The overinvestment of time and money in the care for the child, added to the low contribution to the household finances, reduced the budgetary resources of the family, which reduces social participation and the performance of recreational activities, and impacts on health ${ }^{(6,8,18)}$. Families of children with cerebral palsy have lower income than families of children without deficiencies ${ }^{(17-18)}$. Low income, lack of paid work, and low social participation have been associated with increased stress and poorer psychological health in the parents ${ }^{(3,8,18-19)}$. Conversely, it is noteworthy that the multivariate 
analysis revealed that leisure activities and paid work reduce stress. Furthermore, good family functioning, social support, the use of strategies for coping with stress, increased self-esteem, and sense of competence faced with the situation of caring are protective factors for stress and contribute to better psychological health in the parents ${ }^{(3-4,17,20)}$.

The motor impairment level of the children did not explain the manifestation of stress, however, differences between the extremes (groups: I /II and IV/V) draw attention. Mothers of levels I/II children presented higher stress in the "difficult child" subscale, which evaluates the difficulty that mothers have to deal with the behavioral problems of the children. The children are independent in the gross motor functions such as sitting, walking, running and jumping. However, in these levels emotional and behavioral problems are common: urinating at night; hyperactivity; difficulty sleeping; becoming very dirty; seeking attention; aggression; and mood changes ${ }^{(4,8,10)}$. The physical health of patients in levels IV/V is more compromised, leading to frequent hospitalizations, with pain possibly present as a result of musculoskeletal deformities and other clinical complications. The children need care even for basic functions, such as changing posture, movement, feeding, and hygiene ${ }^{(8,21-22)}$. As can be seen, the care demands are broad and the mothers are certainly overburdened. However, the emotional and behavioral problems are less noticeable, which is justified by the physical limitations and difficulty in communication for the child.

The mothers of adolescents in levels I/II were more stressed than the mothers of adolescents in levels IV/V. Regarding levels IV/V, it is clear to the parents that the impairment of the children is serious and that they are dependent. The prognosis is more easily clarified and expectations are low. Conversely, parents of children classified in levels I/II do not anticipate having dependent children and the expectations are higher $^{(3,16,21)}$. It appears that, for these parents it is more difficult to deal with the fact that they have adolescent children with mild motor impairment, however, who still require constant surveillance and supervision. A study conducted with 101 parents of children and adolescents with cerebral palsy evaluated the association between parental stress and motor impairment level of the children. The authors concluded that parents of children with mild motor impairment presented higher levels of parental stress ${ }^{(23)}$. A theoretical multidimensional model was constructed to evaluate the direct and indirect relationships between the characteristics of the child and the physical and psychological health of 468 caregivers of children with cerebral palsy. Greater care required by those children with greater physical disability, measured by the GMFCS, and the behavioral problems of the children were associated with higher levels of stress and poorer health in the caregivers ${ }^{(3)}$.

A European study of 818 families of children with cerebral palsy, between eight and 12 years of age, found that more than $40 \%$ of the children presented psychological problems, such as hyperactivity, attention deficit, and difficulty in relating to other people. The children with better motor performance presented more psychological problems(21). Two other studies performed using the same sample concluded that the parents of children with greater psychological impairment, communication problems, intellectual disability, and pain had a higher risk of stress ${ }^{(6,22)}$. A longitudinal study of 110 parents of children, nine to 13 years of age, with a three years follow-up, found that the greater the motor impairment, the higher the levels of stress in the parents. According to the authors, maternal stress decreased with the increase in age of the children ${ }^{(8)}$.

The interaction between degree of motor impairment and age group of the children, and maternal stress is still poorly understood, with this mainly being due to the lack of longitudinal studies that have a longer followup period and include adolescents and adults. Studies with this methodological design and qualitative studies could facilitate the comprehension of the impact of the disability on the family, over the years. Most importantly: they would allow the recognition of the resources used by the families that have adapted well. Considering only the age group, mothers of older children (three to nine years and eleven months) presented higher stress in all the subscales and in the total questionnaire. In this stage of life, social contact and exposure increase the possibility of identifying hyperactivity, behavioral problems, and difficulties in performing daily life and school tasks. The results indicate that in this period the mothers had greater difficulty coping with the demands of the children. Actions to promote autonomy, social participation, and the development of coping strategies (scarce or ineffective in this stage) would be useful. This is a time of great expectation and many doubts, as there is concern related to the prognosis, knowing whether the children will meet the expectations and whether they will be well accepted in the social life. In addition, there is a strong relationship between parental stress and the academic performance of the children ${ }^{(24-25)}$. 


\section{Conclusion}

Mothers of children with cerebral palsy are vulnerable to stress, however, the stress factors differ. The results indicated that the mothers presented high levels of parental stress; the proportion was higher in the "parental distress" subscale, which assesses how the needs of the children cause distress and restrict the social participation of the mothers; there were differences in the manifestation of stress between mothers of children with mild and severe motor impairment - mothers of children in levels I/II of the GMFCS presented higher stress in the "difficult child" subscale, which addresses issues related to the behavior of the children; the mothers of adolescents in levels I/II were more stressed than the mothers of adolescents in levels IV/V; the mothers of older children were more stressed than the mothers of younger children and adolescents; and paid work and leisure reduced parental stress. Considering that paid work and leisure activities contribute to reducing maternal stress, the involvement of mothers in these activities is justified. However, this depends on a lot of investment, not only in the reorganization of the family environment, with the division of tasks, but also in the restructuring of public health policies and an increase in cerebral palsy prevention strategies.

It is also important to highlight some limitations of this study: the PSI/SF has not been validated for the Brazilian population, however, was selected due to being an instrument already translated into Portuguese, used in other publications, and the best for evaluating parental stress; the study did not address other influences, such as the relationship with the spouse, the family support, the presence of technical support, and the cultural context; the sample consisted of a population with specific characteristics, including low income and receiving care in institutions, limiting the generalization of the results.

Finally, the contribution of this study to the understanding of cerebral palsy as a public health issue is highlighted. Health professionals need to know which characteristics of the children are more stressful for the mothers and to offer support so that they are able to care for their children without suffering due to the requirements.

\section{References}

1. Magill-Evans J, Darrah J, Pain K, Adkins R, Kratochvil $M$. Are families with adolescents and young adults with cerebral palsy the same as other families? Dev Med Child Neurol. 2001;43(7):466-72.
2. Rosenbaum P, Paneth N, Leviton A, Goldstein M, Bax M. A report: the definition and classification of cerebral palsy. Dev Med Child Neurol. 2007;49(109):8-14.

3. Raina $P$, O'Donnell M, Rosenbaum $P$, Brehaut J, Walter SD, Russell D, et al. The health and well-being of caregivers of children with cerebral palsy. Pediatrics. 2005;115(6):e626-36.

4. Ketelaar M, Volman MJ, Gorter JW, Vermeer A. Stress in parents of children with cerebral palsy: what sources of stress are we talking about? Child Care Health Dev. 2008;34(6):825-9.

5. Prudente COM, Barbosa MA, Porto CC. Relação entre a qualidade de vida de mães de crianças com paralisia cerebral e a função motora dos filhos, após dez meses de reabilitação. Rev. Latino-Am. Enfermagem. 2010;18(2):149-55.

6. Parkes J, Caravale B, Marcelli M, Franco F, Colver A. Parenting stress and children with cerebral palsy: a European cross-sectional survey. Dev Med Child Neurol. 2011;53(9):815-21.

7. Abidin RR. The determinants of parenting behavior. J Clin Child Psychol. 1992;21(4):407-12.

8. Sipal RF, Schuengel C, Voorman JM, Van Eck M, Becher JG. Course of behaviour problems of children with cerebral palsy: the role of parental stress and support. Child Care Health Dev. 2010;36(1):74-84.

9. Butcher PR, Wind T, Bouma A. Parenting stress in mothers and fathers of a child with a hemiparesis: sources of stress, intervening factors and long-term expressions of stress. Child Care Health Dev. 2008;34(4):530-41.

10. Glenn S, Cunningham C, Poole $H$, Reeves D, Weindling M. Maternal parenting stress and its correlates in families with a young child with cerebral palsy. Child Care Health Dev. 2009;35(1):71-8.

11. Dessen MA, Szelbracikowski AC. Crianças com problemas de comportamento exteriorizado e a dinâmica familiar. Interação. 2004;8(2):171-80.

12. Pereira-Silva NL, Dessem MA. Famílias de crianças com síndrome de Down: sentimentos, modos de vida e estresse parental. Interação. 2006;10(2):183-94. 149 p. 13. Minetto MF, Crepaldi MA, Bigras M, Moreira LC. Práticas educativas e estresse parental de pais de crianças pequenas com desenvolvimento típico e atípico. Educ Rev. 2012;(43):117-32.

14. Hiratuka E, Matsukura T S, Pfeifer LI. Adaptação transcultural para o Brasil do Sistema de Classificação da Função Motora Grossa (GMFCS). Rev Bras Fisioter. 2010;14(6):537-44.

15. Silva DBR, Pfeifer LI, Funayama CAR. Sistema de Classificação da Função Motora Grossa ampliado e revisto 
[Internet]. Hamilton (CA); 2010. [acesso 12 ago 2013]. Disponível em: http://motorgrowth.canchild.ca/en/GMFCS/ resources/PORTUGUESE_corrigido-FINALMay12.pdf

16. Ribeiro MFM, Vandenberghe L, Porto CC. Estresse parental em famílias de crianças com paralisia cerebral: revisão integrativa. Cienc Saude Coletiva. 2013;18(6):1705-15.

17. Britner PA, Morog MC, Pianta RC, Marvin RS. Stress and coping: a comparison of self-report measures of functioning in families of young children with cerebral palsy or no medical diagnosis. J Child Fam Stud. 2003;12(3):335-48.

18. Brehaut JC, Kohen DE, Raina P, Walter SD, Russell DJ, Swinton M, et al. The health of primary caregivers of children with cerebral palsy: how does it compare with that of other Canadian caregivers? Pediatrics. 2004;114(2):182-91.

19. Mobarak R, Khan NZ, Munir S, Zaman SS, McConachie $\mathrm{H}$. Predictors of stress in mothers of children with cerebral palsy in Bangladesh. J Pediatr Psychol. $2000 ; 25(6): 427-33$.

20. Wanamaker CE, Glenwick DS. Stress, coping, and perceptions of child behavior in parents of preschoolers with cerebral palsy. Rehabil Psychol. 1998; 43(4):297-312.

21. Parkes J, White-Koning M, Dickinson HO, Thyen $U$, Arnaud C, Beckung $E$, et al. Psychological problems in children with cerebral palsy: a cross-sectional European study. J Child Psychol Psychiatry. 2008;49(4):405-13.

22. Parkes J, McCullough N, Madden A, McCahey E. The health of children with cerebral palsy and stress in their parents. J Adv Nurs. 2009;65(11):2311-23.

23. Park MS, Chung CY, Lee KM, Sung KH, Choi IH, Kim TW. Parenting stress in parents of children with cerebral palsy and its association with physical function. J Pediatr Orthop B. 2012;21(5):452-6.

24. Brossard-Racine M, Waknin J, Shikako-Thomas K, Shevell $M$, et al. Behavioral difficulties in adolescents with cerebral palsy. J Child Neurol. 2013;28(1):27-33.

25. Williford AP, Calkins SD, Keane SP. Predicting change in parenting stress across early childhood: child and maternal factors. J Abnorm Child Psychol. 2007;35(2):251-63. 